\title{
Antidiabetic Studies and Dereplication of the Bioactive Constituents of Anthocleista nobilis G. Don by UHPLC/ESI-QTOF-MS
}

\author{
Philip F. Uzor ${ }^{1}$, Charles 0. Nnadi ${ }^{1,2}$, J oshua E. Ahiabuike ${ }^{1}$ and Helen N. Ani ${ }^{1}$ \\ ${ }^{1}$ Department of Pharmaceutical and Medicinal Chemistry, Faculty of Pharmaceutical Sciences, University of \\ Nigeria, Nsukka 410001, Enugu State, Nigeria \\ ${ }^{2}$ Institut für Pharmazeutische Biologie und Phytochemie, Westfälische Wilhelms-Universität, Münster 48149 \\ Münster, Germany
}

(Received: 29 October, 2017; Accepted: 9 January, 2018; Published (web): 10 June, 2018)

\begin{abstract}
Diabetes mellitus remains a global health challenge and herbal medicines are known to be effective and safe for use in its management. Anthocleista nobilis is used in the traditional management of the disorder but this claimed use has not been validated. The present study was designed to establish and hence validate the use of the plant for the management of diabetes and also identify the bioactive phytoconstituents of the plant. The root and stem bark extracts of the plant were investigated for antidiabetic activity in alloxan-induced diabetic rats. The animals were treated orally with 100,200 and $400 \mathrm{mg} / \mathrm{kg}$ bw of both extracts for seven days. The fasting blood glucose concentration (FBGC) of the animals was monitored for seven days with a glucometer. Ultra-high performance liquid chromatography/electrospray ionization-quadrupole time-of-flight mass spectrometric (UHPLC/ESI-QTOF-MS) technique was adopted for partial dereplication of secondary metabolites of the plant. The extracts significantly $(p<$ $0.5)$ reduced the FBGC of the diabetic animals. Nine previously reported compounds in the genus Anthocleista were successfully dereplicated from the plant and identified to be scopoletin (1), anthocleistol (2), sweroside (3), djalonesone (4), fagaramide (5), lanosta-7, 24-dien-3-one (6), 1-hydroxy-3,7-dimethoxyxanthene (7), djalonensin (8) and secologanin (9). Numerous other prominent peaks were not identified and could be potential novel compounds. The traditional use of A. nobilis in the management of diabetes has been validated in the present study. The identified as well as the unidentified compounds could provide template for guided isolation of the antidiabetic and other bioactive constituents of the plant.
\end{abstract}

Key words: Antidiabetic plant, Anthocleista nobilis; dereplication, diabetes; hypoglycemic effect; phytochemical study.

\section{INTRODUCTION}

Diabetes is a metabolic disease caused by the elevation of blood glucose level as a result of either insulin resistance or by abnormal insulin secretion rate. The complications of diabetes include nephropathy, neuropathy, dermopathy, blindness, hypertension, stroke and gastroparesis. ${ }^{1}$ The disease is a leading cause of death globally despite several recent advances that have been made in its prevention and treatment. The current (2015) estimate by the International Diabetes Federation (IDF) shows that

Correspondence to: Philip F. Uzor

E-mail: philip.uzor@unn.edu.ng; Tel: +234-8037008294

Dhaka Univ. J. Pharm. Sci. 17(1): 19-28, 2018 (June)
415 million adults have diabetes and, by 2040, this will rise to 642 million. The report also shows that every 6 seconds a person dies from diabetes (5.0 million deaths) while $12 \%$ of global health expenditure is spent on diabetes ( $\$ 673$ billion). ${ }^{2}$

Several drugs are currently available for the management of type 2 diabetes (the commonest type of diabetes), but these drugs are associated with side effects such as abdominal pains, hepatic toxicity, weight gain, gastrointestinal discomfort and skin rashes. ${ }^{3}$ Safer and more potent antidiabetic drugs are therefore urgently needed for better glycemic control. Herbal alternatives to the management of chronic disorders such as diabetes are growing in popularity 
because they are considered effective, safe, less expensive, and easily available. Additionally, medicinal plants have been known as an important source of phytochemicals which serve as lead molecules for drug development. ${ }^{4}$

Anthocleista nobilis G. Don (common name: cabbage tree; uko nkirisi in Igbo, Nigeria) is a plant in Gentianaceae family but formerly of the Loganiaceae family (http://www.theplantlist.org/; accessed 18 June, 2017). Various parts of the plant are used for the treatment of several ailments such as constipation, menstrual problems, leprosy, venereal diseases, hernia, haemorrhoids and malaria. ${ }^{5-7}$ Reports have shown that $A$. nobilis is used in Guinea ${ }^{8}$ and in Nigeria ${ }^{9,10}$ for the management of diabetes. In a recent review of Anthocleista genus, Anyanwu et al. ${ }^{11}$ have shown that the claimed use of A. nobilis in the traditional management of diabetes has not been validated. The stem bark was reported to exhibit in vitro antioxidant activity. ${ }^{12}$

In addition, a preliminary phytochemical screening of the stem bark of A. nobilis through standard chemical tests has been reported. ${ }^{12}$ Also there are reports of isolation of sweroside and a secoiridoid (anthocleistol) ${ }^{9}$ as well as lanosta-7,24dien-3-one and lanosta-7,24-dien-3-acetate ${ }^{13}$ from the plant. Despite these reports, a thorough phytochemical profile of the plant has not been studied. ${ }^{11}$ Thus, there are still yet-to-be isolated metabolites from the plant. Since several compounds have been isolated from the Anthocleista genus, ${ }^{11}$ dereplication approach could easily identify the compounds present in the plant species prior to the isolation process. In drug discovery, dereplication of known compounds is crucial for the identification of novel bioactive compounds ${ }^{14}$ since this approach discriminates between previously known and potential novel compounds. The present study was therefore designed to investigate and hence validate the claimed traditional use A. nobilis in the management of diabetes and to profile the putative bioactive constituents of the plant through dereplication approach employing UHPLC/ESIQTOF-MS.

\section{MATERIALS AND METHODS}

Collection and processing of plant material. The leaf, root bark and stem bark of A. nobilis were collected from Nsukka, Enugu State, Nigeria in March 2016. The plant material was identified and authenticated by Mr. Ozioko, a taxonomist with the International Center for Ethnomedicine and Drug Development (InterCEDD), Nsukka. The voucher specimen (InterCEDD/16021) was deposited in the laboratory of the Department of Pharmaceutical and Medicinal Chemistry, University of Nigeria, Nsukka for future reference. The plant materials were allowed to dry under shade and pulverized.

Extraction of plant materials. About $600 \mathrm{~g}$ of each of the pulverized leaf, root bark and stem bark of A. nobilis was extracted separately with $3 \mathrm{~L}$ of $95 \%$ methanol by cold maceration for $48 \mathrm{hrs}$ with occasional shaking. The liquid extracts were filtered and concentrated to afford the dried leaf extract (ALE), root bark extract (ARE) and stem bark extract (ASE).

Animals. Forty five (45) adult Wistar albino rats of either sex (weight: $70.0-114.0 \mathrm{~g}$ ) were purchased from the Department of Veterinary Medicine, University of Nigeria, Nsukka and used for the experiment. The animals were housed in standard animal cages, fed with commercial feed and water $a d$ libitum. The care and handling of animals was in line with the Institutional Ethics Committee and European Community guidelines. ${ }^{15}$

Chemicals and reagents. The solvents used in the experiment were acetonitrile, formic acid, methanol (Sigma Aldrich Chemicals, USA) and distilled water. Other chemicals used were alloxan monohydrate (Sigma Aldrich Chemicals, USA) and glibenclamide (Glanil®,NGC, Nigeria). All the chemicals were of analytical grade.

Antidiabetic studies. The rats were kept fasting overnight for $12 \mathrm{~h}$ with water ad libitum. They were randomly grouped into nine $(\mathrm{n}=5)$ and, following our previously described method with slight modifications, ${ }^{16}$ diabetes was induced by administration (single dose of $150 \mathrm{mg} / \mathrm{kg}$, i.p.) of 
freshly prepared alloxan monohydrate. The experimental protocols were as follows:

Group A- vehicle $(0.2 \mathrm{ml} / \mathrm{kg})$ only,

Group B- alloxan + vehicle $(0.2 \mathrm{ml} / \mathrm{kg})$ (Control),

Group C-alloxan $+100 \mathrm{mg} / \mathrm{kg}$ of ARE,

Group D- alloxan $+200 \mathrm{mg} / \mathrm{kg}$ of ARE,

Group E- alloxan $+400 \mathrm{mg} / \mathrm{kg}$ of ARE,

Group F- alloxan $+100 \mathrm{mg} / \mathrm{kg}$ of ASE,

Group G- alloxan $+200 \mathrm{mg} / \mathrm{kg}$ of ASE,

Group H- alloxan $+400 \mathrm{mg} / \mathrm{kg}$ of ASE,

Group I- alloxan + glibenclamide $(0.2 \mathrm{mg} / \mathrm{kg})$.

The administration of the drug was done (p.o, single daily dose) for 7 days. The fasting blood glucose concentration (FBGC) of the rats was measured on day 1 at $0,1,3,6$ and $9 \mathrm{~h}$ and on day 7 at $0 \mathrm{~h}$ with a glucometer and strips (ACCU-CHEK ${ }^{(\mathrm{R})}$, Roche)

\section{LC-mass spectroscopic analysis (UHPLC-MS)}

Injection and analysis. The crude methanol extracts of the stem bark (ASE) and root bark (ARE) were dissolved separately in $80 \% \mathrm{v} / \mathrm{v}$ aqueous methanol at a defined concentration $(5 \mathrm{mg} / \mathrm{ml})$ with ultra-sonicator and centrifuged for $30 \mathrm{~min}, 3500 \mathrm{rpm}$, room temperature and an aliquot filtered through a $0.45 \mu \mathrm{m}$ Teflon filter and analyzed with UHPLC/ESI-QTOF MS/MS. Thereafter, the detailed metabolite profiles were obtained that consisted of reproducible retention data and exact mass for each of the various constituents present in the extracts. Chromatographic separations were performed on a Dionex Ultimate 3000 RS Liquid Chromatography System with a Dionex Acclaim RSLC 120, C18 column (2.1 x $100 \mathrm{~mm}, 2.2 \mu \mathrm{m})$ using a binary gradient (A: water with $0.1 \% \mathrm{v} / \mathrm{v}$ formic acid; $\mathrm{B}$ : acetonitrile with $0.1 \% \mathrm{v} / \mathrm{v}$ formic acid) at 0.8 $\mathrm{mL} / \mathrm{min}$ : 0 to $9.5 \mathrm{~min}$ : linear from $5 \% \mathrm{~B}$ to $100 \% \mathrm{~B}$; 9.5 to $12.5 \mathrm{~min}$ : isocratic $100 \% \mathrm{~B} ; 12.5$ to $12.6 \mathrm{~min}$ : linear from $100 \% \mathrm{~B}$ to $5 \% \mathrm{~B} ; 12.6$ to $15 \mathrm{~min}$ : isocratic $5 \%$ B. The injection volume was $5 \mu \mathrm{L}$. Eluted compounds were detected using a Dionex Ultimate DAD-3000 RS over a wavelength range of 200-400 nm and a Bruker Daltonics micrQTOF-QII quadrupole/time-of-flight mass spectrometer equipped with an Apollo electrospray ionization (ESI) source in positive mode at $5 \mathrm{~Hz}$ over a mass range of $m / z$ 50-1000 using the following instrument settings: nebulizer gas nitrogen, 5 bar; dry gas nitrogen, $9 \mathrm{~L} / \mathrm{min}, 220^{\circ} \mathrm{C}$; capillary voltage $4500 \mathrm{~V}$; end plate offset $-500 \mathrm{~V}$; transfer time $70 \mu \mathrm{s}$; collision gas nitrogen; collision energy and collision RF settings were combined to each single spectrum of 1000 summations as follows: 250 summations with $20 \%$ base collision energy and $130 \mathrm{Vpp}+250$ summations with $100 \%$ base collision energy and 500 $\mathrm{Vpp}+250$ summations with $20 \%$ base collision energy and $130 \mathrm{Vpp}+250$ summations with $100 \%$ base collision energy and $500 \mathrm{Vpp}$. Base collision energy was $50 \mathrm{eV}$ for precursor ions with a $\mathrm{m} / \mathrm{z}$ less than 500 and then linearly interpolated against $\mathrm{m} / \mathrm{z}$ up to a maximum of $70 \mathrm{eV}$ for precursor ions with a $\mathrm{m} / \mathrm{z}$ of up to 1000. Internal dataset calibration (HPC mode) was performed for each analysis using the mass spectrum of a $10 \mathrm{mM}$ solution of sodium formate in $50 \%$ isopropanol that was infused during LC re-equilibration using a divert valve equipped with a $20 \mu \mathrm{L}$ sample loop.

\section{Data analysis}

(a) Antidiabetic data analysis: The data obtained in the experiments were evaluated with ANOVA followed by Dunnett post hoc t- test (2-sided) using a statistical software (SPSS version 21). The significance threshold was set at $p<0.05$. Results were expressed as mean \pm SEM.

(b) Partial dereplication: The software Bruker Daltonics Profile Analysis 2.0 (Bruker Daltonik $\mathrm{GmbH}$, Germany, 2010) was used to calibrate the raw data (UHPLC-MS chromatograms and mass spectra) and to convert them into $\mathrm{mzXmL}$ format files. These files were processed on MZmine 2.10 (open-source) for peak detection, isotope detection, peak alignment, normalization and peak identification. Peak detection was performed through customized steps as mass detection (centroid module). For peak deconvolution, each chromatogram was deconvoluted into individual 
chromatographic peaks and their respective intensities and areas were extracted. Peak alignment (Join aligner) was used to match relevant peaks across multiple samples under $m / z$ and retention time $\left(t_{R}\right)$ tolerances. Some $5 \%$ of prominent peaks chosen randomly were initially inspected to set further parameters and thresholds in the software. Finally, a list of peaks was generated and their partial identification was performed by querying automatically, in the natural product databases, the exact masses of molecular ions $[\mathrm{M}+\mathrm{H}]^{+}$and common adducts $\left([\mathrm{M}+\mathrm{Na}]^{+},\left[\mathrm{M}+\mathrm{NH}_{4}\right]^{+},[\mathrm{M}+\mathrm{K}]^{+},[2 \mathrm{M}+\mathrm{Na}]^{+}\right)$ (error $=0.005 \mathrm{Da})$. The UHPLC-MS/MS chromatograms of both extracts were automatically dissected (signal to noise ratio > 5). All the MS data were checked for the elution profile of each $\mathrm{m} / \mathrm{z}$ signal and by that cleaned from background signals and signals of overlapping peaks. Additionally, an elution profile for each compound was generated as a chromatogram. The deconvoluted peaks were selected based on their relative intensities, as indication of the level of composition in the extract.

\section{RESULTS AND DISCUSSION}

Extractive yield. The yields of the extracts were as follows: leaf extract (ALE) $4.2 \%$, root bark extract (ARE) $3.0 \%$ and stem bark extract (ASE) $3.8 \%$.

Antidiabetic activity of $\boldsymbol{A}$. nobilis. The data from the present study show that both A. nobilis root and stem bark extracts produced a significant ( $\mathrm{p}<$ 0.05) reduction of the FBGC of the diabetic rats on day 7 but only the stem bark lowered the FBGC (p < 0.05 ) on the first day (Table 1). The stem bark extract, at the $9^{\text {th }}$ hour of day 1 , produced significant $(\mathrm{p}<0.001)$ reduction in FBGC of $67 \%, 83.2 \%$ and $85.9 \%$ for the respective doses of $100 \mathrm{mg} / \mathrm{kg}, 200$ $\mathrm{mg} / \mathrm{kg}$ and $400 \mathrm{mg} / \mathrm{kg}$ compared to reductions ( $\mathrm{p}>$ 0.05 ) of $20 \%, 22.6 \%$ and $17.7 \%$ for the similar doses of the root bark extract (Figure 1). On day 7, the stem bark, at the three doses, also reduced $(\mathrm{p}<0.01)$ and normalized the FBGC $(<100 \mathrm{mg} / \mathrm{dl})$ by $78.2 \%$, $80.9 \%$ and $76.0 \%$ respectively better than the root bark extract, which effected respective reductions ( $\mathrm{p}$ $<0.05)$ of $57.6 \%, 47.8 \%$ and $44.6 \%$ on the same day.
Thus, the stem bark extract produced better reductions in the FBGC of the diabetic rats on days 1 and 7. Interestingly, the stem bark extract normalized the blood glucose (FBGC $<100 \mathrm{mg} / \mathrm{dl}$ ) of the diabetic rats on days 1 and 7 similar to the standard drug, glibenclamide, which produced a reduction ( $\mathrm{p}<$ $0.05)$ of $59.2 \%$ on day $1\left(9^{\text {th }}\right.$ hour $)$ and $76.4 \%$ on day 7.

LC-mass spectroscopic analysis (UHPLCMS/MS). Following complete dereplication of the TIC $\mathrm{m} / \mathrm{z}$ signals, a total of 238 and $236 \mathrm{~m} / \mathrm{z}$ signals were detected in ASE and ARE respectively, with 234 of the signals from both extracts being similar (Figure 2). Three signals of ASE, representing compounds 8, 9 and an unidentified peak (tR 13.0 min; $m / z$ 399.4), were not found in ARE. Their accurate +ESI-MS spectra $(\mathrm{m} / \mathrm{z})$ are shown in Figure 3. Nine (1-9) previously known compounds from the genus Anthocleista were identified in both extracts (Figure 4) as scopoletin (1), anthocleistol (2), sweroside (3), djalonesone (4), fagaramide (5), lanosta-7, 24-dien-3-one (6), 1-hydroxy-3,7dimethoxyxanthene (7), djalonensin (8) and secologanin (9). These identified compounds belong to coumarin, secoiridoid, iridoid glycoside, dibenzo$\alpha$-pyrone, alkaloid, triterpene, xanthone, phthalide and secoiridoid glycoside, respectively. The chromatographic and spectral profiles are presented in Table 2. Numerous other peaks could not be identified in both extracts. Among the identified compounds, compound $\mathbf{2}$ was relatively the most abundant in both extracts by peak area (6636012 and 9644954 for ARE and ASE respectively).

In the present study, we have investigated the phytoconsituents of $A$. nobilis as well as its antidiabetic properties in order to validate the acclaimed traditional use of the plant in the management of diabetes. We studied the leaf, root bark and stem bark of the plant but our preliminary data (not presented here) showed that the leaf did not significantly $(p>0.05)$ reduce the FBGC of the animals while both the root and stem bark extracts did lower $(\mathrm{p}<0.05)$ the FBGC. Hence the root and 
stem bark were chosen for the present study. The significant reduction of the FBGC by both extracts indicates the antidiabetic activity of the plant. The antidiabetic activity is, however, more pronounced with the stem bark (ASE) than the root bark (ARE) as indicated by the data. The present findings are in agreement with the traditional usage of the stem bark $^{8}$ and the root bark ${ }^{9}$ for the management of diabetes but not the leaf. Other species of Anthocleista such as A. vogelii, A. schweinfurthii and A. djalonensis have been shown to possess antidiabetic property. ${ }^{17-19}$ However, to the best of our knowledge, this is the first report of the antidiabetic activity of A. nobilis. The mechanism of action of the plant was not investigated. However, since the plant exhibited similar antidiabetic effect comparable to glibenclamide, it is possible that the mode of antidiabetic action of the plant is as an insulin secretagogue.

Table 1. Effect of A. nobilis root and stem bark extracts on the FBGC of diabetic rats.

\begin{tabular}{|c|c|c|c|c|c|c|c|c|}
\hline \multirow[t]{4}{*}{ Group } & \multirow[t]{4}{*}{ Treatment } & \multicolumn{7}{|c|}{ FBGC (mg/dl) } \\
\hline & & \multirow[t]{3}{*}{ Basal $^{\mathrm{a}}$} & \multicolumn{5}{|c|}{ Day 1} & \multirow[t]{3}{*}{ Day 7} \\
\hline & & & \multicolumn{5}{|c|}{ Time (h) after administration } & \\
\hline & & & 0 & 1 & 3 & 6 & 9 & \\
\hline A & $\begin{array}{l}\text { Vehicle }(0.2 \\
\mathrm{mL} / \mathrm{kg})\end{array}$ & $\begin{array}{l}96 \\
\pm 4.59\end{array}$ & $\begin{array}{c}65.6 \\
\pm 1.3^{* * *}\end{array}$ & $\begin{array}{c}90.8 \\
\pm 2.9^{* * *}\end{array}$ & $\begin{array}{c}88.4 \\
\pm 7.2^{* * * *}\end{array}$ & $\begin{array}{c}99.6 \\
\pm 5.2^{* * * *}\end{array}$ & $\begin{array}{c}81.0 \\
\pm 4.2^{* * * *}\end{array}$ & $\begin{array}{c}66.8 \\
\pm 5.7^{* * * *}\end{array}$ \\
\hline B & $\begin{array}{l}\text { Alloxan }+ \\
\text { vehicle (Control) }\end{array}$ & $\begin{array}{l}95.0 \\
\pm 4.59\end{array}$ & $\begin{array}{l}356.4 \\
\pm 22.0\end{array}$ & $\begin{array}{l}327.0 \\
\pm 20.6\end{array}$ & $\begin{array}{l}303.0 \\
\pm 20.3\end{array}$ & $\begin{array}{l}292.1 \\
\pm 23.3\end{array}$ & $\begin{array}{l}275.2 \\
\pm 23.5\end{array}$ & $\begin{array}{l}215.3 \\
\pm 18.6\end{array}$ \\
\hline $\mathrm{C}$ & $\begin{array}{l}\text { Alloxan }+100 \\
\mathrm{mg} / \mathrm{kg} \text { of ARE }\end{array}$ & $\begin{array}{l}115.1 \\
\pm 2.3^{*}\end{array}$ & $\begin{array}{l}377.0 \\
\pm 43.9\end{array}$ & $\begin{array}{l}358.0 \\
\pm 55.2\end{array}$ & $\begin{array}{l}371.4 \\
\pm 52.9\end{array}$ & $\begin{array}{l}346.8 \\
\pm 47.4\end{array}$ & $\begin{array}{l}301.6 \\
\pm 32.6\end{array}$ & $\begin{array}{c}160.0 \\
\pm 0.67^{*}\end{array}$ \\
\hline $\mathrm{D}$ & $\begin{array}{l}\text { Alloxan }+200 \\
\mathrm{mg} / \mathrm{kg} \text { of ARE }\end{array}$ & $\begin{array}{l}100.2 \\
\pm 1.56\end{array}$ & $\begin{array}{l}317.2 \\
\pm 36.3\end{array}$ & $\begin{array}{l}363.2 \\
\pm 68.2\end{array}$ & $\begin{array}{l}322.2 \\
\pm 43.2\end{array}$ & $\begin{array}{l}308.8 \\
\pm 40.5\end{array}$ & $\begin{array}{l}245.6 \\
\pm 22.6\end{array}$ & $\begin{array}{l}165.7 \\
\pm 0.7^{*}\end{array}$ \\
\hline $\mathrm{E}$ & $\begin{array}{l}\text { Alloxan }+400 \\
\mathrm{mg} / \mathrm{kg} \text { of ARE }\end{array}$ & $\begin{array}{l}111.9 \\
\pm 5.1\end{array}$ & $\begin{array}{l}447.4 \\
\pm 65.4\end{array}$ & $\begin{array}{l}484.2 \\
\pm 72.1\end{array}$ & $\begin{array}{l}467.0^{*} \\
\pm 72.6\end{array}$ & $\begin{array}{l}458.2 \\
\pm 75.2^{*}\end{array}$ & $\begin{array}{r}368.4 \\
\pm 58.5\end{array}$ & $\begin{array}{l}248.0 \\
\pm 64.0\end{array}$ \\
\hline $\mathrm{F}$ & $\begin{array}{l}\text { Alloxan }+100 \\
\mathrm{mg} / \mathrm{kg} \text { of ASE }\end{array}$ & $\begin{array}{l}101.2 \\
\pm 7.2\end{array}$ & $\begin{array}{l}444.8 \\
\pm 58.8\end{array}$ & $\begin{array}{l}422.8 \\
\pm 66.0\end{array}$ & $\begin{array}{l}353.8 \\
\pm 30.8\end{array}$ & $\begin{array}{c}133 \\
\pm 33.1^{*}\end{array}$ & $\begin{array}{c}143.8 \\
\pm 47.9^{*}\end{array}$ & $\begin{array}{c}96.8 \\
\pm 23.5^{* *}\end{array}$ \\
\hline G & $\begin{array}{l}\text { Alloxan }+200 \\
\mathrm{mg} / \mathrm{kg} \text { of ASE }\end{array}$ & $\begin{array}{l}96.1 \\
\pm 4.7\end{array}$ & $\begin{array}{l}256.6 \\
\pm 44.2\end{array}$ & $\begin{array}{l}303.6 \\
\pm 63.0\end{array}$ & $\begin{array}{l}263.8 \\
\pm 40.2\end{array}$ & $\begin{array}{c}66.2 \\
\pm 14.8^{* * *}\end{array}$ & $\begin{array}{c}43 \\
\pm 8.4^{* * * *}\end{array}$ & $\begin{array}{c}49.4 \\
\pm 21.4^{* * * *}\end{array}$ \\
\hline $\mathrm{H}$ & $\begin{array}{l}\text { Alloxan }+400 \\
\mathrm{mg} / \mathrm{kg} \text { of ASE }\end{array}$ & $\begin{array}{l}98.0 \\
\pm 4.2\end{array}$ & $\begin{array}{l}272.2 \\
\pm 62.8\end{array}$ & $\begin{array}{l}287.6 \\
\pm 62.5\end{array}$ & $\begin{array}{l}332.6 \\
\pm 13.9\end{array}$ & $\begin{array}{l}191.8 \\
\pm 53.1\end{array}$ & $\begin{array}{c}38.4 \\
\pm 9.9^{* * * *}\end{array}$ & $\begin{array}{c}65.2 \\
\pm 13.3^{* * * *}\end{array}$ \\
\hline I & $\begin{array}{l}\text { Alloxan }+ \\
\text { glibenclamide } \\
(0.5 \mathrm{mg} / \mathrm{kg})\end{array}$ & $\begin{array}{l}104.2 \\
\pm 3.1\end{array}$ & $\begin{array}{l}417.0 \\
\pm 18.6\end{array}$ & $\begin{array}{l}378.3 \\
\pm 24.1\end{array}$ & $\begin{array}{l}264.4 \\
\pm 27.1\end{array}$ & $\begin{array}{c}189.5 \\
\pm 9.2\end{array}$ & $\begin{array}{c}170.2 \\
\pm 10.0^{*}\end{array}$ & $\begin{array}{c}98.6 \\
\pm 25.4^{* *}\end{array}$ \\
\hline
\end{tabular}

Results are expressed as mean \pm SEM $(\mathrm{n}=5) ; * \mathrm{p}<0.05$, ** $<<0.01, * * * \mathrm{p}<0.001$ as compared with control group (Group B) (One Way ANOVA followed by Dunett t-test, 2-sided); ${ }^{a}$ Basal refers to the FBGC before alloxan administration; ARE = root extract of A. nobilis, ASE $=$ stem bark extract of $A$. nobilis.

In order to quickly identify the likely bioactive principles responsible for the antidiabetic activity of the plant, dereplication studies were done. By the combination of: (i) UHPLC-MS full scan total ion chromatograms (TIC) $\mathrm{m} / \mathrm{z}$, (ii) acquisition of compounds, hitherto, undetected in TIC by positive selected ion monitoring (SIM) through literature search for reported spectral and chromatographic data, where available, from the genus Anthocleista (iii) UV fingerprints and chromatographic retention times, and (iv) integrating the spectra data for each identified peak (retention times, UV profile and $\mathrm{m} / \mathrm{z}$ ), the chemical structures of compounds 1-9 were identified from A. nobilis. The fact that the compounds have previously been isolated from several plant species in the Anthocleista genus (including $A$. vogelii, $A$. djalonensis, and $A$. grandiflora) could be additional proof of the presence 
of the compounds in A. nobilis. Moreover, our preliminary phytochemical screening by standard chemical tests (data not shown) revealed the presence of alkaloids, flavonoids, glycosides, steroids and terpenoids in both extracts. Also the genus Anthocleista is known to contain secondary metabolites such as alkaloids, xanthones, phthalides, secoiridoids and terpenes, ${ }^{20}$ many of which have been isolated and reported. ${ }^{9,21-26}$ Hence, these identified compounds and/or other yet-to-be characterized compounds of the extracts could be responsible for the biological activities of the extracts. These phytoconstituents could be acting either singly or in combination with synergistic effect.

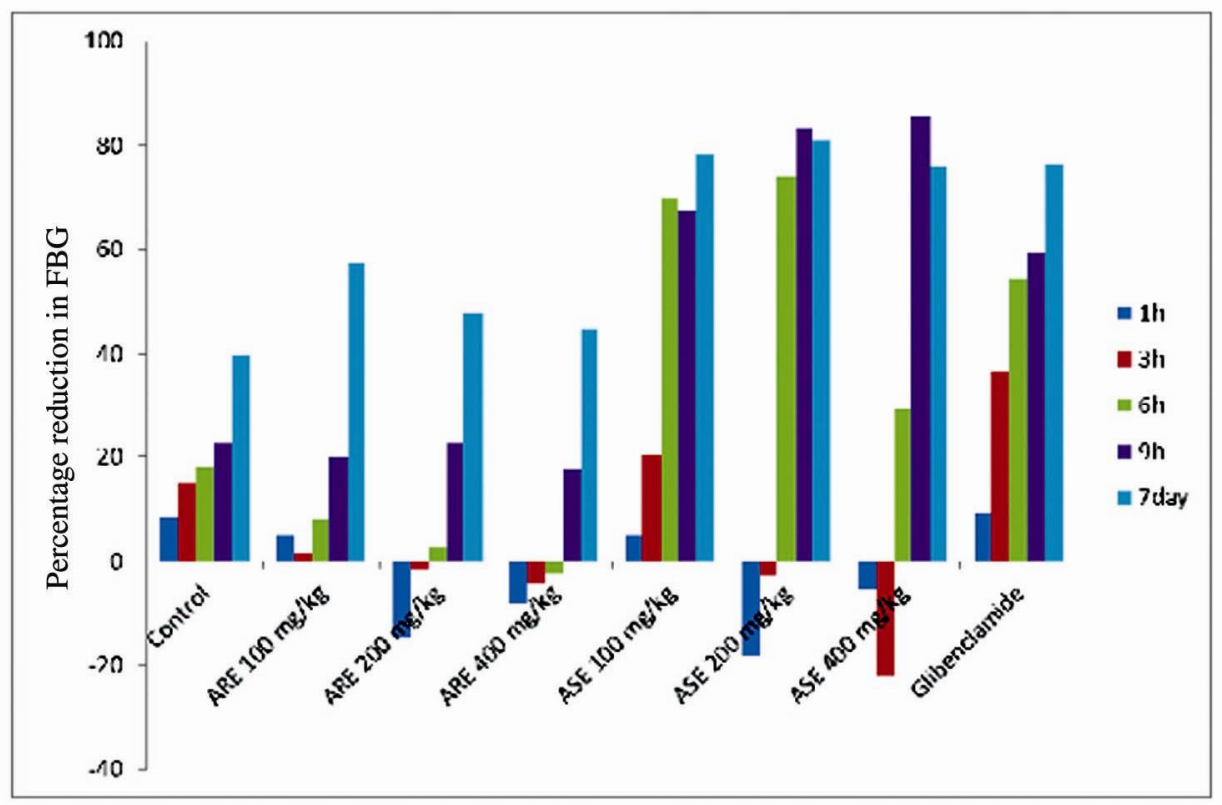

Figure 1. Reduction (\%) in FBGC of the diabetic rats by the extracts and glibenclamide. Percentage reduction in FBGC was calculated with reference to the value of FBGC at $0 \mathrm{~h}$; ARE $=$ root extract of $A$. nobilis, $\mathrm{ASE}=$ stem bark extract of A. nobilis.

Table 2. Chromatographic and spectra profiles (tR, UV max. and +ESI adducts) of identified compounds in ARE and ASE.

\begin{tabular}{|c|c|c|c|c|c|c|}
\hline \multirow[t]{2}{*}{ Compound } & \multirow{2}{*}{$\begin{array}{c}\mathrm{tR} \\
(\mathrm{min})\end{array}$} & \multirow{2}{*}{$\begin{array}{l}\text { UV max. } \\
\quad(\mathrm{nm})\end{array}$} & \multirow[t]{2}{*}{ Molecular ion } & \multicolumn{2}{|c|}{ Peak Area } & \multirow[t]{2}{*}{ Reference } \\
\hline & & & & ARE & ASE & \\
\hline Scopoletin (1) & 1.9 & 232,342 & $215[\mathrm{M}+23]^{+}$ & 324863 & 90377 & 24 \\
\hline Anthocleistol (2) & 2.5 & 207 & $201[\mathrm{M}+1]^{+}$ & 6636012 & 9644954 & 9 \\
\hline Sweroside (3) & $\begin{array}{l}4.0,4.4, \\
4.5\end{array}$ & $\begin{array}{l}201,254, \\
320\end{array}$ & $359[\mathrm{M}+1]^{+}$ & 1329704 & 251539 & $22,24,25,27-31$ \\
\hline Djalonensone (4) & 4.3 & $\begin{array}{l}247,283, \\
331\end{array}$ & $295[\mathrm{M}+23]^{+}$ & 340580 & 213104 & 31,32 \\
\hline Fagaramide (5) & 4.3 & 240,260 & $248[\mathrm{M}+1]^{+}$ & 337680 & 388766 & 24,30 \\
\hline Lanosta-7,24-dien-3-one (6) & 5.0 & 272,334 & $447[\mathrm{M}+23]^{+}$ & 184835 & 297926 & 13 \\
\hline $\begin{array}{l}\text { 1-Hydroxy-3,7- } \\
\text { dimethoxyxanthone (7) }\end{array}$ & 10.8 & 226 & $293[\mathrm{M}+23]^{+}$ & 211113 & 271549 & 26,33 \\
\hline Djalonensin $(\mathbf{8})^{*}$ & 7.4 & 215,256 & $305[\mathrm{M}+39]^{+}$ & N/A & 132579 & 30,31 \\
\hline Secologanin $(\mathbf{9}) *$ & 13.4 & 254,270 & $411[\mathrm{M}+23]^{+}$ & N/A & 141799 & 22,25 \\
\hline
\end{tabular}




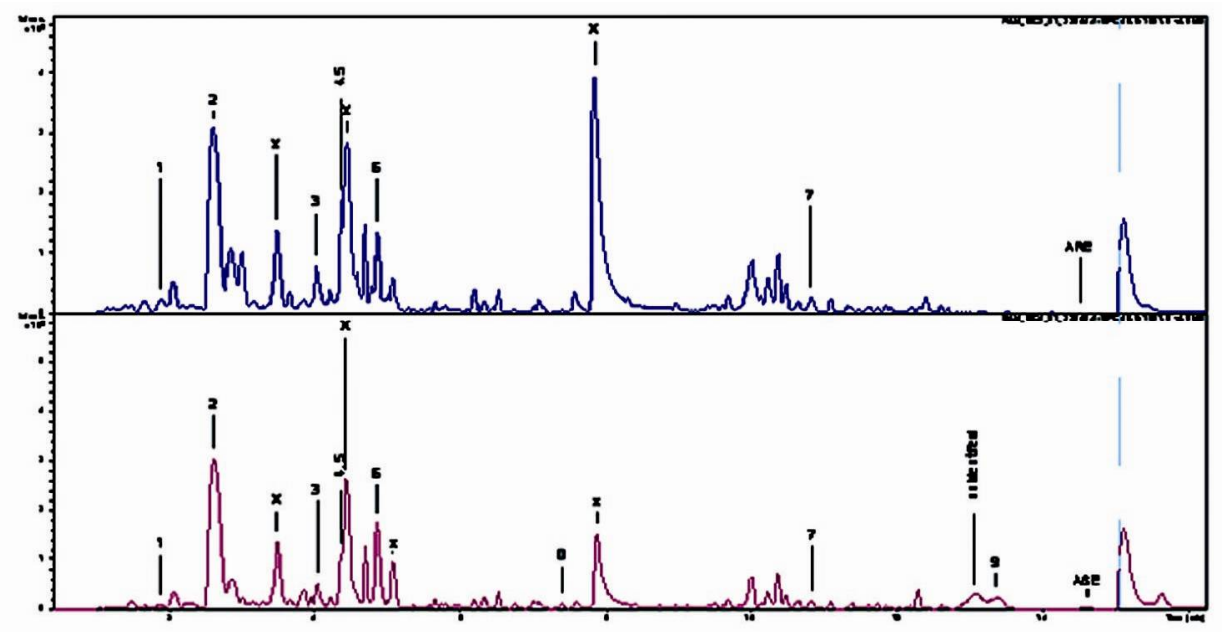

Figure 2. UHPLC/ESI-QTOF-MS/MS chromatograms of ARE and ASE. X represents the most abundant peaks; 1-7 are the compounds identified in both ARE and ASE while 8, 9, and an unidentified compound (tR 13.0 min.) are found in ASE only.
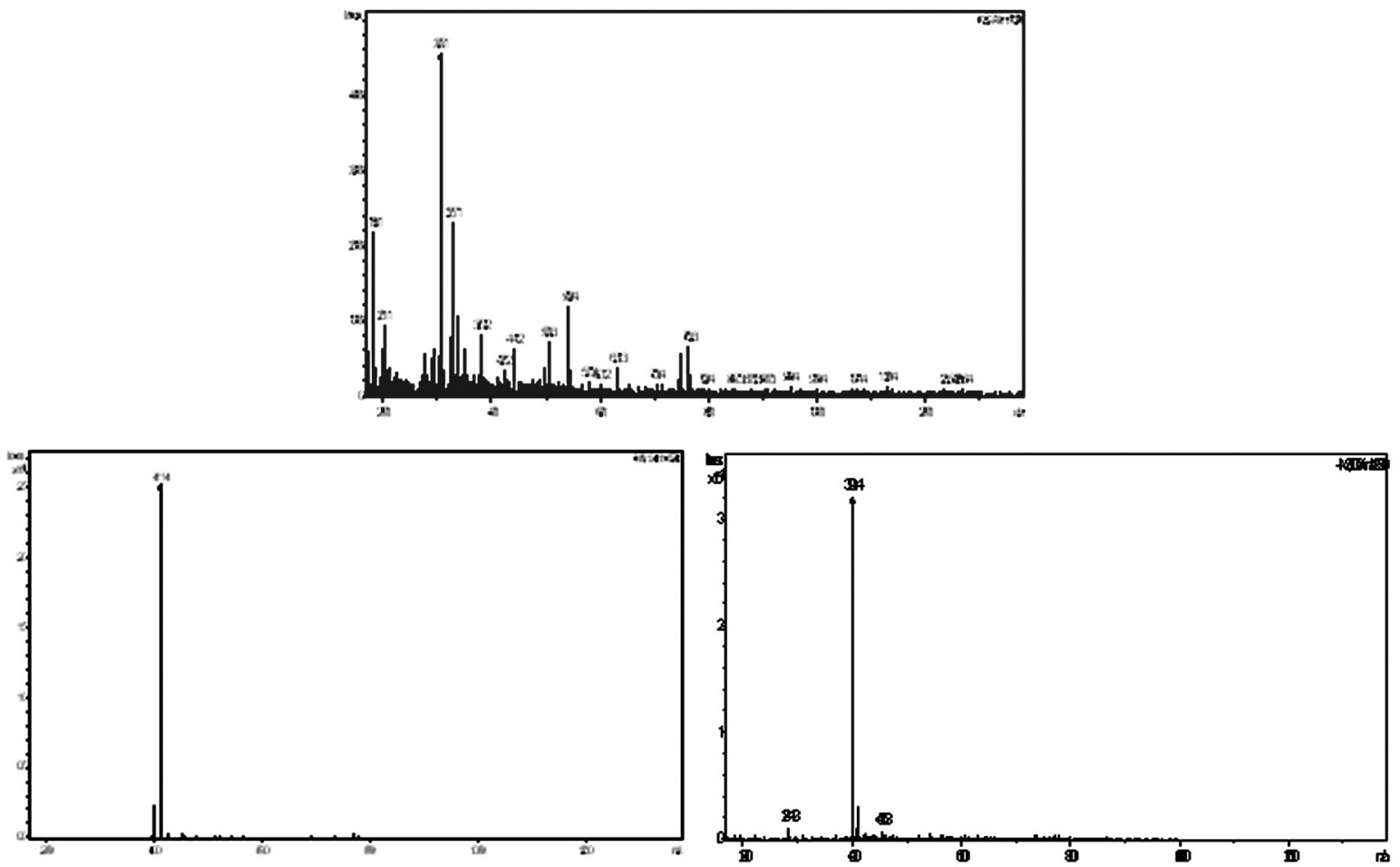

Figure 3. +ESI-MS spectra $(\mathrm{m} / \mathrm{z})$ of compounds specific to ASE (spectra are placed in a clockwise direction starting with the top left spectrum for compounds 8,9 and the unidentified compound, respectively).

To further explain the difference in biological activity data of the root and stem bark extracts, all the identified $\mathrm{m} / \mathrm{z}$ signals from the extracts were crossmatched. Three $\mathrm{m} / \mathrm{z}$ signals 8 (tR $7.4 \mathrm{~min}, \mathrm{~m} / \mathrm{z}$ 305.1920 ), 9 (tR $13.4 \mathrm{~min}, \mathrm{~m} / \mathrm{z} 411.0962$ ) and one unidentified compound (tR $13.0 \mathrm{~min}, \mathrm{~m} / \mathrm{z}$ 399.4081) were found in ASE only. However, of the three $\mathrm{m} / \mathrm{z}$ signals identified from the ASE only, two (8 and 9) were found to have been previously isolated as djalonensin (8) and secologanin (9) from the genus Anthocleista. The presence of these three compounds more in ASE compared to ARE could be responsible 
for higher antidiabetic activity recorded by the former. Interestingly, the most abundant phytochemicals contained in the plant extracts (marked $X$ in Figure 2) and numerous other unidentified compounds have not yet been isolated or reported from this family and could present an impressive lead compounds as antidiabetic agents. Furthermore, it is also interesting to note that the dereplication strategy could identify compounds $\mathbf{2}$ and 6 which were previously isolated from the root bark $^{9}$ and bark $^{13}$ of $A$. nobilis respectively. In the present study, these compounds (2 and 6) were identified as prominent peaks in both the root and stem bark extracts. The identification of these two compounds is a further evidence to validate the UHPLC/ESI-QTOF-MS dereplication strategy adopted in the present study.<smiles>COc1cc2ccc(=O)oc2cc1O</smiles><smiles>Cc1cc(O)cc2oc(=O)c3c(O)cc(O)cc3c12</smiles>

4<smiles>COc1cc(O)c2c(=O)c3cc(OC)ccc3oc2c1</smiles><smiles>C=CC(CO)C1CCOC(=O)C1CO</smiles><smiles>C=C(/C=C/c1ccc2c(c1)OCO2)NCC(C)C</smiles><smiles>C=C[C@H]1[C@H](O[C@@H]2O[C@H](O)[C@@H](O)[C@H](O)[C@H]2O)OC=C2C(=O)OCC[C@@]21C</smiles><smiles>CC(C)=CCC[C@H](C)[C@H]1CC[C@]2(C)C3=CC[C@H]4C(C)(C)C(=O)CC[C@]4(C)[C@]3(C)CC[C@]12C</smiles>

6<smiles>C=C[C@H]1[C@H](O[C@@H]2O[C@H](CO)[C@@H](O)[C@H](O)[C@H]2O)OC=C(C(=O)OC)[C@H]1CC=O</smiles>

Figure 4. Dereplicated compounds from ARE (1-7) and ASE (1-9)

Despite the reported antidiabetic activity of several species of the genus Anthocleista and the numerous compounds isolated, most of the compounds have not been subjected to scientific scrutiny for antidiabetic activity ${ }^{11}$ besides a few of them such as bauerenone and bauerenol which were isolated from the root of $A$. schweinfurthii and shown to be promising alpha amylase inhibitors $\left(\mathrm{IC}_{50}\right.$ of 9.8 $\pm 0.04 \mu \mathrm{M}$ and $5.8 \pm 0.14 \mu \mathrm{M}$ respectively). ${ }^{17}$ Thus detailed chemical and pharmacological studies are needed to isolate and identify the actual compound(s) responsible for the antidiabetic activity of $A$. nobilis based on the reports of the present study.

\section{CONCLUSION}

The results of the present study have validated the acclaimed use of A. nobilis in the traditional management of diabetes. The stem bark of the plant possesses better antidiabetic activity than the root bark. The adopted dereplication strategy which 
employed UHPLC/ESI-QTOF-MS was shown to be useful for the profiling of the secondary metabolites of $A$. nobilis. The strategy tentatively provided nine compounds of different chemical classes which could be responsible for the bioactivity of the plant. Interestingly, some major peaks could not be dereplicated and could be source of new compounds from the genus in a targeted isolation and identification strategies. Research in this direction is ongoing in our laboratory.

\section{Authors' contributions}

PFU designed the work, contributed in the antidiabetic and phytochemical studies, literature search, statistical analysis, wrote the first draft of the manuscript and did the overall supervision of the work. CON participated in the phytochemical studies, literature search and manuscript writing. JEA and HNA participated in carrying out the antidiabetic studies, statistical analysis and literature search. All authors agreed on the final draft of the manuscript.

\section{Conflict of interest}

Authors declare nil

\section{Funding}

This research did not receive any specific grant from funding agencies in the public, commercial, or not-for-profit sectors.

\section{REFERENCES}

1. American Diabetes Association, 2017. Available: http://www.diabetes.org/living-with-diabetes/complications/? loc=lwd-slabnav. Accessed: 18 June, 2017.

2. International Diabetes Federation (IDF), 2015. IDF diabetes atlas - 7th edition. http://www.diabetesatlas.org/keymessages.html. Accessed 18 June, 2017

3. Rahim, A.A., Mohamad, J. and Alias, Z. 2014. Antidiabetic activity of aqueous extract of Leptospermum flavescens in alloxan induced diabetic rats. Sains Malays. 43, 1295-1304.

4. Uzor, P.F. and Osadebe, P.O. 2016. Antidiabetic compounds from Combretum Dolichopetalum and its endophyte. Lap Lambert Academic Publishing, Germany.

5. Burkill, H.M. 2000. The useful plants of West Tropical Africa, vol. 3. Families J-L. Kew, Royal Botanic Gardens.
6. Dalziel, J.M. 1937. The useful plants of West Tropical Africa. Crown Agents, London.

7. Iwu, M.M. 2014. Handbook of African Medicinal Plants, second edition. CRC Press, Boca Raton, FL.

8. Diallo, A., Traore, M.S., Keita, S.M., Balde, M.A., Keita, A., Camara, M., Van Miert, S., Pieters, L. and Balde, A.M. 2012. Management of diabetes in Guinean traditional medicine: an ethnobotanical investigation in the coastal lowlands. $J$. Ethnopharmacol. 144, 353-361.

9. Madubunyi, I.I., Adam, K.P. and Becker, H. 1994. Anthocleistol, a new secoiridoid from Anthocleista nobilis. Z. Naturforsch. C 49, 271-272.

10. Soladoye, M. O., Chukwuma, E. C. and Owa, F. P. 2012. An 'avalanche' of plant species For the traditional cure of diabetes mellitus in south-western Nigeria. J. Nat. Prod. Plant Res. 2, 60-72.

11. Anyanwu, G.O, Nisar-ur-Rehman, Onyeneke, C.E. and Rauf, K. 2015. Medicinal plants of the genus Anthocleista - A review of their ethnobotany, phytochemistry and pharmacology. J. Ethnopharmacol. 175, 648-667.

12. Ngwoke, K.G., Anusi I.A., Eze, P.M., Okezie, U.M., Abba C.C. and Abonyi, D.O. 2015. Phytochemical and antioxidant properties of stem bark extracts of Anthocleista nobilis. Eur. J. Med. Plant. 8, 107-111.

13. Gosse, B.K., Bryson T.A. and Gokou, T. 1997. Novel triterpenes from Alstonia boonei and Anthocleista nobilis. Bull. Chem. Soc. Ethiop. 11, 159-161.

14. Kildgaard, S., Mansson, M., Dosen, I., Klitgaard, A., Frisvad, J.C., Larsen, T.O. and Nielsen K.F. 2014. Accurate dereplication of bioactive secondary metabolites from marine-derived fungi by UHPLC-DAD-QTOFMS and a MS/HRMS library. Marine Drugs 12, 3681-3705.

15. EEC, 1986. EEC Council Directive 86/609/EEC of 24 November 1986 on the approximation of laws, regulations and administrative provisions of the Member States regarding the protection of animals used for experimental and other scientific purposes. Official J. Europ. Commun. L358: 1-29.

16. Uzor, P.F., Osadebe, P.O., Omeje, E.O. and Agbo, M.O. 2014. Bioassay guided isolation and evaluation of the antidiabetic principles of Combretum dolichopetalum root. British J. Pharm. Res. 4, 2155-2171.

17. Mbouangouere, R.N., Tane, P., Ngamga, D., Khan, S.N., Choudhary, M.I. and Ngadjui, B.T. 2007. A new steroid and $\alpha$-glucosidase inhibitors from Anthocleista schweinfurthii. Res. J. Med. Plants 1, 106-111.

18. Olubomehin, O.O., Abo, K.A. and Ajaiyeoba, E.O. 2013. Alpha-amylase inhibitory activity of two Anthocleista species and in vivo rat model anti-diabetic activities of Anthocleista djalonensis extracts and fractions. J. Ethnopharmacol.146, 811-814.

19. Osadebe, P.O., Uzor, P.F., Omeje, E.O., Agbo, M.O. and Obonga, W.O. 2014. Hypoglycemic activity of the extract and fractions of Anthocleista vogelii (Planch) stem bark. Tropical J. Pharm. Res. 13, 1437-1443. 
20. Chapelle, J.P. 1974. Chemical constituents of the leaves of Anthocleista vogelii. Planta Med. 26, 301-304.

21. Bierer, D.E., Gerber, R.E., Jolad, S.D., Ubillas, R.P., Randle, J., Nauka, E., Latour, J., Dener, J.M. and Fort, D.M. 1995. Isolation, structure elucidation, and synthesis of irlbacholine, 1, 22-bis[2-(trimethylammonium) ethoxy] phosphinyl] oxy] docosane: a novel antifungal plant metabolite from Irlbachia alata and Anthocleista djalonensis. J. Org. Chem. 60, 70227026.

22. Chapelle, J.P. 1976. Vogeloside and secologanic acid, secoiridoid glucosides from Anthocleista vogelii. Planta Med. 29, 268-274.

23. Jensen, S.R. 1992. Systematic implications of the distribution of iridoids and other Chemical compounds in the Loganiaceae and other families of the Asteridae. Annals Missouri Botanical Gardden 79, 284-302.

24. Mulholland, D.A., Crouch, N.R., Coombes, P.H., Magadula, J.J. and Randrianarivelojosia, M. 2005. Unusual triterpenoids from African medicinal plants In: 11th NAPRECA Symposium Book of Proceedings, Antananarivo, Madagascar, pp. 20-26.

25. Tene, M., Tane, P., Kuiate, J.R., Tamokou, J.D. and Connolly, J.D.M. 2008. Anthocleistenolide a new rearranged nor-secoiridoid derivative from the stem bark of Anthocleista vogelii. Planta Med. 74, 80-83.

26. Valentão, P., Andrade, P.B., Silva, E., Vicente, A., Santos, H., Bastos, M.L. and Seabra, R.M. 2002. Methoxylated xanthones in the quality control of small centaury (Centaurium erythraea) flowering tops. J. Agri. Food Chem. 50, $460-463$.
27. Baba, H. and Usifoh, C.O. 2011. Phytochemical investigation and anti-inflammatoryproperty of ethanol-water extract of the roots of Anthocleista djalonensis A. Chev. (Gentianiaceae). Afr. J. Biotech. 10, 6598-6600.

28. Chapelle, J.P. 1973. Isolement de derives seco-iridoides d'Anthocleista zambesiaca. Phytochemistry 12, 1191-1192.

29. Deng, S, West, B.J. and Jensen, C.J 2013. UPLC-TOF-MS characterization and identification of bioactive iridoids in Cornus mas fruit. Journal of Analytical Methods in Chemistry Volume 2013, Article ID 710972, 7 pages

30. Okorie, D.A. 1976. A new phthalide and xanthones from Anthocleista djalonensis and Anthocleista vogelli. Phytochemistry 15, 1799-1800.

31. Onocha, P.A., Okorie, D.A., Connolly, J.D. and Roycroft, D.S. 1995. Monoterpene diol, iridoid glucoside and dibenzo$\alpha$-pyrone from Anthocleista djalonensis. Phytochemistry 40, 1183-1189.

32. Onocha, P.A., Okorie, D.A., Connolly, J.D., Krebs, H.C., Meier, B. and Habermehl, G.G. 2003. Cytotoxic activity of the constituents of Anthocleista djalonensis and their derivatives. Nigerian J. Natur. Prod. Med. 7, 58-60.

33. Monte, F.J.Q., Soares, F.P. and Braz-Filho, R. 2001. A xanthone from Shultesia guianensis. Fitoterapia 72, 715-716. 